\title{
ТЕХНОЛОГИИ ДИСТАНЦИОННОГО МОНИТОРИНГА ОКРУЖАЮЩЕЙ СРЕДЫ ПРИ ОПРЕДЕЛЕННЫХ ЭКСТРЕМАЛЬНЫХ СИТУАЦИЯХ
}

\author{
И. В. Суровцева \\ ИРИНА ВЯЧЕСЛАВОВНА СУРОВЦЕВА - соискатель степени кандидата наук Научно-инжинирингового \\ иентра «Перспективные научно-технические проекты» МИРЭА-Российский технологический универси- \\ mem,E-mail: surovceva@mirea.ru.
}

119454, Москва, Россия, пр. Вернадского, д. 78. МИРЭА - Российский технологический университет (РТУ МИРЭА).

В статье показана реализуемость технологий дистанциионного мониторинга при экстремальных ситуациях, связанных с экологической обстановкой, диагностикой сейсмической опасности и радиоактивным загрязнением окружающей среды. Обозначены критерии оценки и факторы экологического состояния акваторий Мирового океана. Представлены результаты объединения технологических возможностей расчета концентрации хлорофилла по данным гиперспектрального прибора Нурегіоп космического апnарата EO-1. Приведень результаты обработки данных бортовой аппаратуры космических аппаратов CHAMP и DEMETER для периодов сейсмической активности. Рассмотрена классификация факторов радиационной опасности. Обоснована перспектива разработки и внедрения эффективных методов дистаниионного мониторинга и контроля радиоактивного загрязнения по диагностическим параметрам в окружающей среде.

Ключевые слова: дистанционный мониторинг окружающей среды, экстремальная ситуация, природные и антропогенные факторы, экологическая обстановка, сейсмическая опасность, радиоактивное загрязнение.

\section{TECHNOLOGIES OF REMOTE ENVIRONMENTAL MONITORING IN CERTAIN EMERGENCY SITUATIONS}

\author{
I. V. Surovceva \\ 78 Vernadsky Avenue, Moscow, 119454, Russia. MIREA - Russian Technological University (RTU - MIREA),
}

The article focuses on the implementability of remote monitoring technologies in emergencies related to the environmental situation, seismic hazard assessment and radioactive pollution of the environment. The assessment criteria and factors of ecological condition of the global ocean are defined. The results of combined technological developments to determine chlorophyll concentration according to the data from EO-1 Hyperion Hyperspectral Imager are presented. The results of data processing from onboard equipment of CHAMP and DEMETER satellites for periods of seismic activity are given. The classification of radiation hazard factors is considered. The prospects of development and implementation of effective methods to monitor remotely and control radioactive pollution based on environmental diagnostic parameters are justified.

Key words: remote environmental monitoring, emergency, natural and man-made factors, environmental situation, seismic hazard, radioactive pollution. 
Мониторинг окружающей среды - это комплексная система наблюдений за состоянием окружающей среды, оценка и прогноз происходящих в ней изменений под воздействием природных и антропогенных факторов [1]. Степень антропогенного воздействия на окружающую среду оценивается по интенсивности загрязнения приземного слоя атмосферы, снижению плодородия почв, запасов и качества пресной воды, по уменьшению количества минеральных ресурсов и т.п.

При опасных ситуациях возникают явления или процессы, способные поражать людей, наносить материальный ущерб, разрушительно действовать на окружающую среду. Наиболее серьезные и масштабные разновидности опасных ситуаций - экстремальные и чрезвычайные, хотя такое деление является условным [2]. Для анализа и прогнозирования развития, например, опасной экологической ситуации в глобальном и региональном масштабах необходимо изучение различных геофизических процессов, антропогенных эффектов, а также факторов, которые их вызывают.

Классификация видов мониторинга окружающей среды основывается на методах наблюдения (таблица 1): мониторинг по физико-химическим и биологическим показателям, дистанционный мониторинг [3].

Во всем мире активно развиваются различные методы изучения окружающей среды, среди которых важное значение имеет дистанционный мониторинг. Его актуальность обосновывается ухудшающейся экологической обстановкой, а также необходимостью решения геологических, геофизических, метеорологических, гидрофизических и других задач. Поэтому задачи дистанционного мони- торинга окружающей среды в соответствии с их научной и прикладной направленностью разделяют на пять ключевых проблем [4]:

1. Контроль погодных и климатических факторов с целью достоверного прогнозирования погоды и изменения климата, в том числе и геофизических условий в околоземном космическом пространстве.

2. Контроль за состоянием источников загрязнения атмосферы, воды и почвы с целью обеспечения природоохранных органов федерального и регионального уровня информацией для принятия управленческих решений.

3. Оперативный контроль чрезвычайных ситуаций (ЧС) природного, технологического, экологического, биолого-социального и военного характеров (пожары, землетрясения, химические и радиационные загрязнения, затопление, биологическое заражение и др.) с целью эффективного планирования и своевременного проведения мероприятий по ликвидации их последствий. Сюда входит определение факта ЧС, его координатная и временная привязка, оценка масштабов распространения и тяжести последствий ЧС.

4. Информационное обеспечение проведения земельной реформы, рационального земле- и лесоиспользования и хозяйственной деятельности.

5. Создание динамической модели Земли как экологической системы с целью прогнозирования нарушений экологического баланса и разработка мероприятий по сохранению среды обитания человека:

- выявление и исследование глобальных изменений в лито-, гидро-, крио-, атмо- и биосфере;

Таблица 1

\section{Классификация мониторинга окружающей среды}

\section{Виды мониторинга \\ Характеристика методов наблюдения}

\begin{tabular}{ll}
\hline Химический & $\begin{array}{l}\text { Система наблюдений за химическим составом (природного и антропогенного } \\
\text { происхождения) атмосферы, осадков, поверхностных и подземных вод, почв, } \\
\text { растительности, вод океанов и морей, животных и за динамикой распространения } \\
\text { химических загрязняющих веществ. }\end{array}$ \\
\hline Физический & $\begin{array}{l}\text { Система наблюдений за влиянием физических процессов и явлений на окружающую } \\
\text { среду (наводнения, вулканизм, землетрясения, цунами, засухи и т.д.) }\end{array}$ \\
\hline Биологический & $\begin{array}{l}\text { Мониторинг, осуществляемый с помощью биоиндикаторов (т.е. таких организмов, } \\
\text { по наличию, состоянию и поведению которых судят об изменениях в среде). }\end{array}$ \\
\hline Экобиохимический & $\begin{array}{l}\text { Мониторинг, базирующийся на оценке двух составляющих окружающей среды } \\
\text { (химической и биологической). }\end{array}$ \\
\hline Дистанционный & $\begin{array}{l}\text { Авиационный, космический мониторинг с применением космических аппаратов (КА), } \\
\text { оснащенных радиометрической аппаратурой, способной осуществлять активное } \\
\text { зондирование изучаемых объектов и регистрацию опытных данных. }\end{array}$ \\
\hline
\end{tabular}


- исследование взаимосвязей между физическими, химическими и биологическими земными процессами и влияния на них солнечной активности;

- выявление закономерностей в глобальных изменениях природы Земли.

В интересах экологического мониторинга особенно актуальным является изучение природной среды в глобальном масштабе, в том числе водной поверхности Мирового океана. Надежным для оценки экологического состояния акваторий является принцип биоиндикации, объектом которого выбираются океанические сообщества фитопланктона. При существенном росте фитопланктона (вспышка цветения) по сравнению с характерными показателями для исследуемой экосистемы, водная поверхность становится зеленее (рисунок 1).

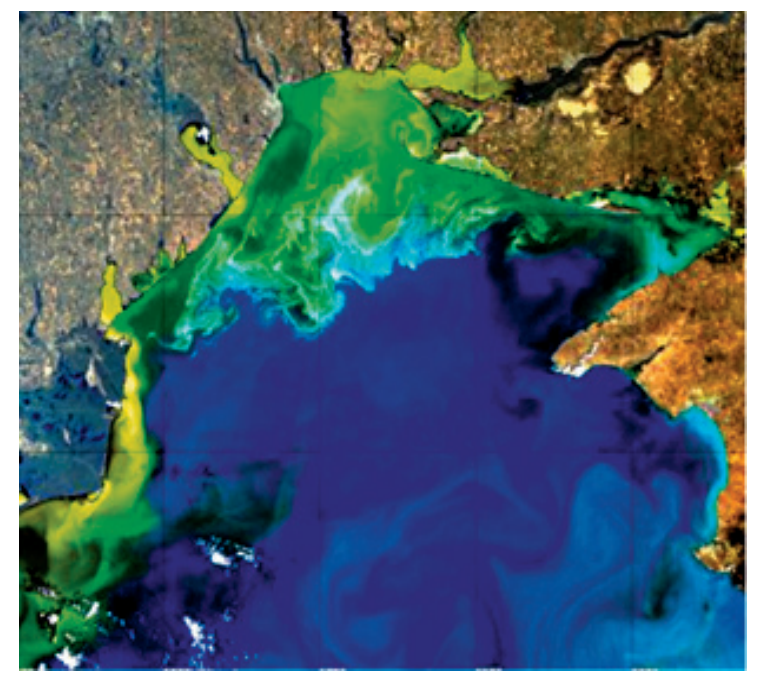

Рис. 1. Аномальное цветение вод в северо-западной части Черного моря по данным прибора MERIS KA Envisat 16.07.2010

Вспышки цветения, как правило, сопровождаются увеличением концентрации хлорофилла и приводят к интенсивному образованию органических пленок биогенного происхождения в результате массового отмирания клеток фитопланктона, что рассматривается как критерий повышения биологической продуктивности и свидетельствует о неблагоприятной экологической обстановке. Поэтому, за базовый критерий оценки экологического состояния акваторий принимается биологическая продуктивность вод [5]. В качестве ее показателей (критерии оценки) рассматривается концентрация хлорофилла и зоны пространственной локализации биогенных пленок на морской поверхности (рисунок 2).

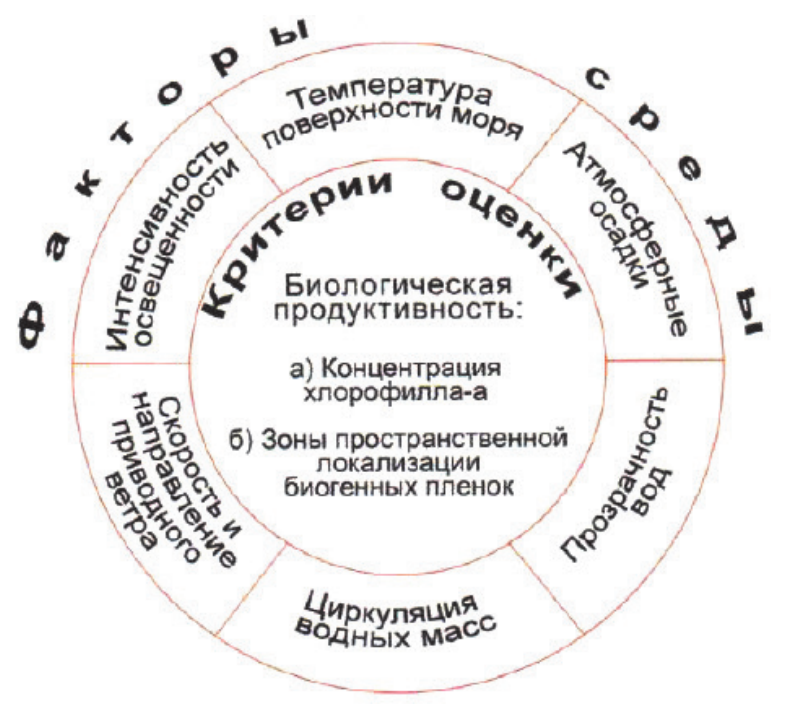

Рис. 2. Критерии оценки и факторы экологического состояния акваторий

Одним из перспективных направлений дистанционного мониторинга для исследования объектов земной поверхности является технология гиперспектральной съемки.

Для определения концентрации хлорофилла оптимальными являются данные оптических сканеров. Спутниковые измерения позволяют осуществлять долговременные квазинепрерывные наблюдения, охватывающие весь Мировой океан. В связи с этим, при участии автора, разработаны и программно реализованы алгоритмы обработки гиперспектральных изображений (ГСИ) аэрокосмических систем дистанционного зондирования Земли в интересах экологического мониторинга и получены следующие результаты [1]:

1. Предложена и апробирована методика определения концентрации хлорофилла по данным гиперспектрального прибора Hyperion KA EO-1 на базе двухканального и трехканального алгоритмов обработки изображений.

2. Разработан обобщенный алгоритм обработки ГСИ водной поверхности и реализующая его вычислительная программа на языке IDL.

3. Проведена идентификация данных по причине избыточной информативности ГСИ. Выполнена географическая привязка. Получены количественные характеристики концентрации хлорофилла по результатам обработки 16 снимков гиперспектрального прибора Hyperion и построены карты визуализации распределения изучаемого параметра.

4. Для валидации результатов работы использованы данные спектрорадиометра MODIS KA Aqua, обработка которых проведена посредством разработки функциональной блок-схемы и еe peaлизации на языке VBA. 
5. Проведено оценивание точности результатов обработки ГСИ. Выявлена лучшая адаптируемость двухканального алгоритма к другим данным гиперспектральной аппаратуры.

Оценивание качества оптических изображений при мониторинге техногенных объектов и явлений подробнее изложены в [6].

В геофизике пристальное внимание уделяется комплексным проблемам, лежащим на пересечении различных областей знаний. Многолетнюю заинтересованность автора вызывает состав ионосферы и плотность электронной концентрации, а также морфология и динамика пространственновременных характеристик ионосферных неоднородностей [7].

Ионосферные эффекты, связанные с сейсмической активностью, определяют повышенный интерес многих исследователей. Ведь эти опасные природные явления проявляются не только в литосфере и в атмосфере, но и ионосфере, где они диагностируются за несколько часов или дней как до, так и после землетрясения. Известно, что перед сильными землетрясениями за несколько дней (часов) в ионосфере наблюдаются неоднородности, характеризуемые существенными возмущениями некоторых параметров среды.

Одним из актуальных прикладных направлений является наблюдение за состоянием локальных областей ионосферы над тектоническими разломами в литосфере, что позволяет своевременно диагностировать повышенную сейсмическую опасность.

В последнее время совершенствование мониторинга ионосферных предвестников землетрясений связано с использованием сигналов глобальных навигационных систем GPS/ГЛОНАCC/ GALILEO, позволяющих определить пространственное распределение и динамику полного электронного содержания в ионосфере.

Дистанционные методы ионосферных исследований имеют свою специфику, что определяет разработку методического аппарата для решения поставленных задач и выбор целевой радиофизической аппаратуры. Поэтому, востребованными научно-прикладными задачами являются адаптация методики выбора рационального состава научной аппаратуры и разработка специального программного обеспечения для обработки экспериментальных данных.

В работах [8-14] с участием автора диагностировались неоднородности, имеющие под собой сейсмологическую причину возникновения, и показаны результаты исследований, связанные с геофизической информацией:

1. Для обработки результатов измерений разработаны программы визуализации и отбора дан- ных KA DEMETER и KA CHAMP, а также алгоритм и программа обработки данных бортовой научной аппаратуры КА, реализующие метод наложения эпох с целью выявления аномалий в измерениях электронной плотности ионосферы в заданном временном интервале, которые предопределяют наличие неоднородных структур в среде. В итоге, выявлены землетрясения, для которых получены выбросы электронной концентрации в ионосфере для обоих КА, не связанные с солнечной активностью, и произошедшие за несколько дней до сейсмического события.

2. Обоснован и экспериментально реализован способ обработки спутниковых данных с использованием межквартильного интервала, что позволило выполнить диагностику ионосферных неоднородностей, обусловленных подготовкой землетрясений.

3. Предложен комплекс параметрических и непараметрических методов математической статистики, позволяющий исследовать электромагнитную эмиссию над сейсмоактивными регионами для повышения вероятности обнаружения неоднородностей в ионосфере.

4. Запатентован (в соавторстве) способ оперативного обеспечения потребителей спутниковой информацией на основе данных космических аппаратов и аппаратно-программный комплекс для его реализации.

Диагностика изменчивости, например, ионной и электронной концентрации в ионосфере с помощью бортовой научной аппаратуры КА над районами радиоактивных выбросов вблизи поверхности Земли и в нижних слоях тропосферы позволит получить информацию о пространственном распространении радиоактивных загрязнений. Такая экстремальная ситуация будет способствовать локальной ионизации в тропосфере со значительными изменениями ее электрических характеристик, что отразится на состоянии ионосферы.

В настоящее время радиоактивное загрязнение окружающей среды является первоочередной проблемой вследствие того, что один из основных источников этого вида загрязнения - ядерная энергетика, развивается быстрыми темпами. На рисунке 3 представлена классификация факторов радиационной опасности [15].

Наибольшую опасность для здоровья человека представляют антропогенные факторы, которые загрязняют окружающую среду как радиоактивными элементами, так и радиационными излучениями. Риск радиационной опасности оценивается вероятностью получения дозы облучения с последующими заболеваниями. Наиболее опасны стронций и цезий, которые трудно выводятся 


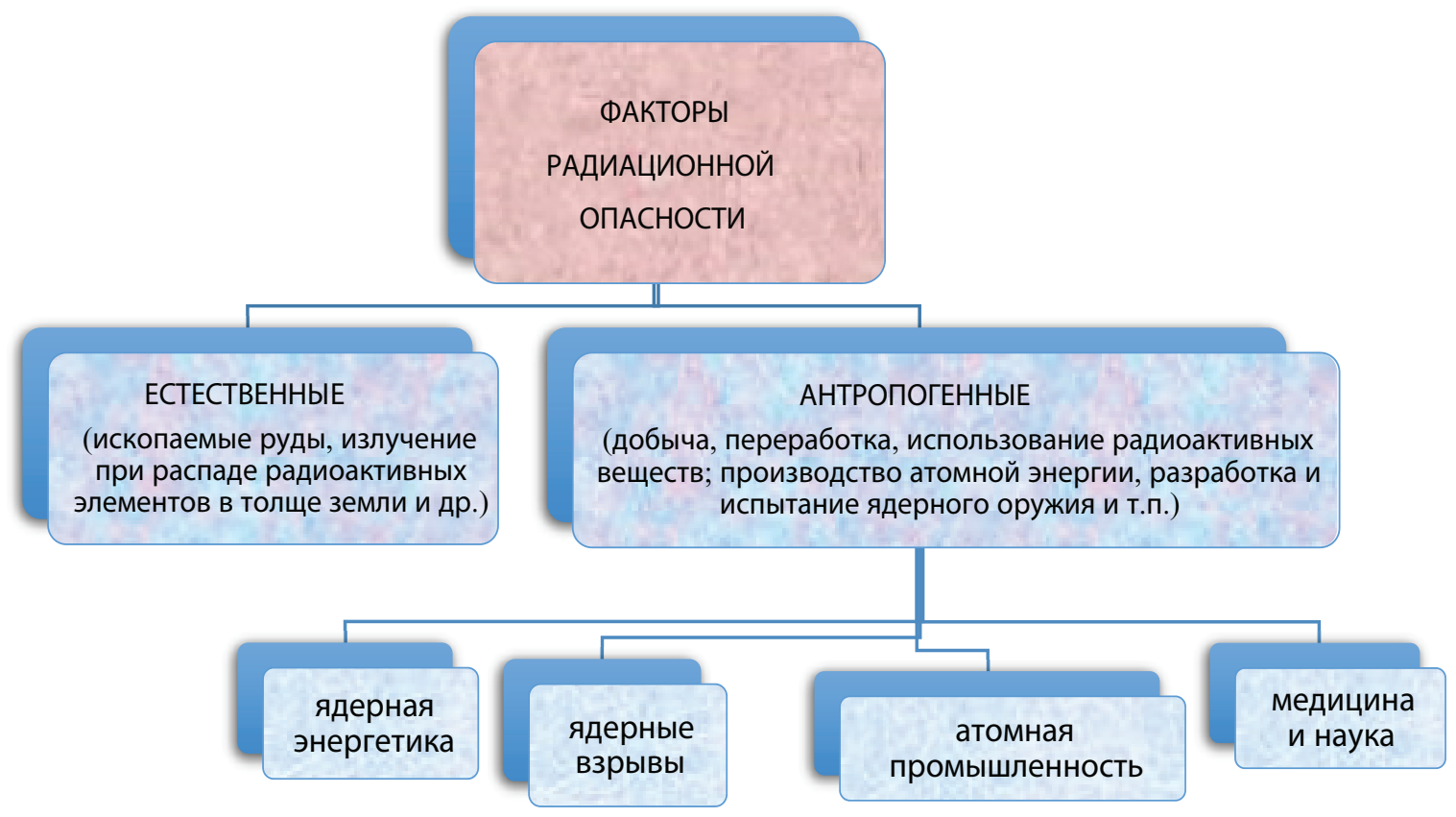

Рис. 3. Классификация факторов радиационной опасности

из организма. Следует также отметить распространение радиоактивных загрязнений вследствие применения в региональных конфликтах боеприпасов, содержащих обедненный уран.

Кроме того, атомная промышленность и ядерная энергетика являются основными источниками радиоактивных отходов (РАО), особенно опасных для всего живого на планете, что создало проблему захоронения, утилизации и складирования РАО.
В связи с вышеперечисленным, все большую актуальность приобретает разработка и внедрение эффективных методов дистанционного обнаружения и контроля радиоактивного загрязнения окружающей среды по диагностическим параметрам, используя технологические возможности, которые представлены в таблице 2 [16].

Для обоснования дальнейших перспективных исследований важно отметить, что изменения

Таблица 2

Возможности дистанционного мониторинга при радиоактивном загрязнении окружающей среды

\section{Диагностические параметры}

\section{Изменения в окружающей среде и технологии их регистрации}

\begin{tabular}{ll}
\hline $\begin{array}{l}\text { Малые газовые } \\
\text { составляющие }\end{array}$ & $\begin{array}{l}\text { Быстрые ион-молекулярные реакции ионизированной атмосферы приводят к изменению } \\
\text { концентраций малых газовых составляющих, регистрация которых возможна, например, } \\
\text { с помощью метода газокорреляционной ИК-радиометрии. }\end{array}$ \\
\hline $\begin{array}{l}\text { Ионосферный } \\
\text { отклик }\end{array}$ & $\begin{array}{l}\text { Ионизация атмосферы приводит к изменению основных электрических характеристик } \\
\text { в цепи тропосфера-ионосфера. Эти возмущения могут быть зарегистрированы } \\
\text { в ионосфере с помощью бортового ионозонда. }\end{array}$ \\
\hline $\begin{array}{l}\text { Нейтральный } \\
\text { кластер }\end{array}$ & $\begin{array}{l}\text { Во влажной атмосфере, подверженной радиоактивному воздействию, при определенных } \\
\text { условиях наблюдается радиоизучение, которое может быть зарегистрировано } \\
\text { специальными радиоспектрометрами. }\end{array}$ \\
\hline
\end{tabular}

Латентное тепло Под действием ионизирующего излучения в приземном слое в зоне радиоактивного выброса происходит резкое падение влажности воздуха. 
в окружающей среде при радиоактивном загрязнении на земной поверхности и в нижних слоях атмосферы, а также при потенциальной радиационной опасности, могут быть диагностированы посредством реализации технологии СВЧ-радиометрии с учетом коррекции требований, предъявляемых к бортовому СВЧ-радиометру и комплексу приема и обработки целевой информации.

Таким образом, мониторинг окружающей среды представлен как комплексная система наблюдений за изменениями в среде под воздействием природных и антропогенных факторов.

Показана перспектива реализации технологий дистанционного мониторинга при экстремальных ситуациях, связанных с экологической обстановкой, диагностикой сейсмической опасности и радиоактивным загрязнением окружающей среды. При этом, дистанционные методы позволяют, например, детализировать тематическую составляющую карт концентрации хлорофилла, определяют возможность оперативной диагностики, что особенно востребовано при обнаружении процессов или явлений, характеризующихся высокой степенью опасности и динамичности во времени.

В зависимости от целевых задач КА состав их бортовой научной аппаратуры может быть различным, поэтому для комплектования ее рационального состава рекомендуется использовать методики и результаты, приведенные в $[17,18]$.

\section{Лumepamypa}

1. Суровиева И.В., Калошин И.Б., Кузнеиов В.В., Скрипачев В.О. Обработка гиперспектральных изображений в интересах экологического мониторинга Земли / XV Международная научно-техническая конференция «Оптические методы исследования потоков» ОМИП-2019, МЭИ, Москва (24-28 июня 2019). - М.: Издательство «Перо», 2019. С. 290-301.

2. Основные понятия и определения, классификация чрезвычайных ситуаций // [Электронный ресурс] URL: https://studopedia.ru/5 21650 ocnovnie-ponyatiya-i-opredeleniya-klassifikatsiya-chrezvichaynih-situatsiy.html.

3. Экологический мониторинг атмосферы: практикум для бакалавров направления подготовки 20.03.01 «Техносферная безопасность» по профилю «Инженерная защита окружающей среды»/ сост. Е.Н. Калюкова. - Ульяновск: УлГТУ, 2015. 131 с.

4. Михайлов В.Ф., Брагин И.В., Брагин С.И. Микроволновая спутниковая аппаратура дистанционного зондирования Земли: Учеб. пособие / СПбГУАП. СПб., 2003. 404 c.

5. Андреева 3.В., Верещака Т.В. Сборник статей по итогам науно-технических конференций / Приложение к журналу Изв. вузов: Геодезия и аэрофотосъемка. 2011. №6. Вып. 4. С. 3-4.
6. Кузнеиов В.В., Суровиева И.В., Калошин И.Б., Гельфман T.Э. Оценка качества оптических изображений при мониторинге техногенных объектов и явлений / Фундаментальные проблемы системной безопасности: Материалы школы-семинара молодых ученых (13-15 сентября 2017). - Воронеж-Севастополь: Издательство «Цифровая полиграфия», 2017. С. 130133.

7. Суровиева И.В. Технологии приёма, обработки и распределения геофизической информации / XIV Всероссийская научная конференция «Технологии и материалы для экстремальных условий», Туапсе, Россия (16-20 сентября 2019). - М.: МЦАИ РАН, 2019. C. 272-280.

8. Kaloshin I., Kuznetsov V., Skripachev V., Surovceva I. Capabilities evaluation of spaceborne scientific equipment for geophysical applications / MATEC Web of Conferences 102, 01024 (2017) V International Forum for Young Scientists "Space Engineering” DOI: 10.1051/matecconf/201710201024.

9. Суровиева И.В., Скрипачев В.О., Барсуков А.И., Полушковский Ю.А., Пирхавка А.П. Анализ и обработка данных бортовой геофизической аппаратуры для оценки сейсмо-ионосферной возмущенности // В сб. Информатика: проблемы, методология, технологии материалы XVI Международной научно-методической конференции. Воронеж, 2016. С. 329 334.

10. Суровиева И.В., Барсуков А.И., Скрипачев В.О., Тихомирова Н.A. Комплексное применение вычислительных программ для обработки данных бортовой научной аппаратуры. Международный научный журнал «Современные технологии и ИТобразование». nov. 2016. V. 12. N. 4. P. 117-124. ISSN 2411-1473.

11. Суровиева И.В., Барсуков А.И., Скрипачев В.О., Полушковский Ю.А., Пирхавка А.П. Использование метода наложения эпох для выявления предвестников природных катастроф // Фундаментальные проблемы системной безопасности: III школа-семинар молодых ученых (26-28 мая 2016) в 2 ч. Ч. II. - Елец: Елецкий государственный университет им. И.А. Бунина, 2016. С. 163-168.

12. Скрипачев В.О., Суровиева И.В., Барсуков А.И. и др. Результаты обработки данных бортовой геофизической аппаратуры для выявления сейсмической активности // Вопросы электромеханики. Труды ВНИИЭМ. Материалы V Международной научнотехнической конференции «Актуальные проблемы создания космических систем дистанционного зондирования Земли». - М.: АО «Корпорация «ВНИИЭМ», 2017. C. 159-167.

13. Kaloshin I., Skripachev V., Surovceva I., Kuznetsov V. Application of satellites system based on different heights for ionospheric disturbances monitoring / VI International Forum for Young Scientists «Space Engineering 2018». - MATEC Web of Conferences 158, 01015 (2018).

14. Патент РФ на изобретение №2465617. Способ и аппаратно-программный комплекс для приема и об- 
работки заявок от внешних потребителей на проведение спутниковой съемки, комплексной обработки спутниковых данных и формирования выходных информационных продуктов для внешних потребителей / Суровцева И.В., Скрипачев В.О., Полушковский Ю.А., Спиричев Д.Л. - МПК: G01S; заявлен 20.07.11; опубликован 27.10.12.

15. Методы экологического мониторинга // [Электронный ресурc] URL: ru.wikipedia.org/wiki/.
16. Боярчук К.А., Карелин А.В., Макриденко Л.А. Труды НПП ВНИИЭМ «Вопросы электромеханики». 2005. T. 102. C. 183-209.

17. Скрипачев В.О., Суровиева И.В., Умнов В.О., Калошин И.Б., Харламов А.Г. International Journal of Open Information Technologies. 2017. V. 5. N. 4. P. 7-11.

18. Калошин И.Б., Харламов А.Г., Скрипачев В.О., Суровцева И.В., Иванов В.К. Сибирский журнал науки и технологий. 2017. Т. 18. №4. С. 868-875. 